DOI: 10.26794/2226-7867-2019-9-1-X-X

УДК 323

ГАЛАС Марина Леонидовна - доктор исторических наук, профессор, главный научный сотрудник департамента политологии и массовых коммуникаций Финансового университета при Правительстве РФ (125993, Россия, г. Москва, Ленинградский пр-кт, 49; MLGalas@fa.ru)

\title{
ИМПУЛЬС СОВЕТСКИХ ИДЕЙ «МЯГКИХ» РЕФОРМ В СОВРЕМЕННОЙ МОДЕЛИ ГОСУДАРСТВА КНР
}

\begin{abstract}
Аннотация. Россия исторически выстраивает с Китаем взаимовыгодные экономические, политические, оборонно-стратегические отношения и культурные связи. Современная геополитика Российской Федерации особое значение придает евразийскому вектору в его прагматичном понимании. Поскольку формирование модели современного Китая обусловлено внутренними (государственное администрирование, трудовые, сырьевые, производственные, сбытовые ресурсы, структура народного хозяйства, культурные традиции, общественный строй, состав народонаселения и др.) и внешними (финансовоинвестиционные, геополитические, военно-стратегические, миграционные факторы, инфраструктура, состояние мирового рынка и др.) факторами, в статье прослеживается влияние исторического опыта советских идей «мягких» реформ на политико-правовые основы государственного строя Китая и его экономический базис.
\end{abstract}

В данном аспекте автор вводит в широкий оборот документы Государственного архива социально-политической истории (РГАСПИ).

Ключевые слова: модель современного государства, политико-правовые основы, идеи политической либерализации, исторический опыт, «мягкая сила»

$\Pi$ ри рассмотрении процесса формирования модели современного государства КНР становится очевидным прямое и косвенное воздействие советских инициатив, концептов, реформ.

Политическую основу государства КНР составляют: марксизм-ленинизм, теоретическое наследие Мао Цзэдуна, Дэн Сяопина, идеи тройного представительства, сформулированные в ноябре 2002 г. на XVI съезде КПК в докладе Генерального секретаря ЦК КПК Цзян Цзэмина ${ }^{1}$, научная концепция развития и идеи Си Цзиньпина².

Из преамбулы Конституции КНР следует, что специфика государства определена его историческим развитием с древнейших времен до «коренных перемен» XX в. (Синьхайская революция 1911 г. и новая демократическая революция 1949 г. под руководством КПК).

Механизм государственного строительства КНР основан на регулятивноохранительном социалистическом объективном праве, нормативно систематизирующем общеобязательные для всех правила поведения, не допускающем свободы действий вне зоны законодательных запретов, а рамочно дозволяющем только законодательно разрешенное. Принцип демократического централизма, принципиально не допускающий плюрализма идей, конституционно объединен с принципом социалистической демократии, основанной на соци-

\footnotetext{
1 Представление требований развития передовых производительных сил страны, прогрессивного направления китайской культуры, коренных интересов китайского народа, объединенное задачей борьбы за реализацию основополагающих интересов государства и народа посредством разработки верной партийной линии, курса и политики.

2 Конституция Китайской Народной Республики от 04.12.1982 (с поправками от 12 апреля 1988 г. и 29 марта 1993 г., 15 марта 1999 г., 14 марта 2004 г., 11 марта 2018 г.).
} 
альном равноправии и прямом народовластии. Конституционный дуализм выражен в законодательном объединении приоритета социалистической собственности и ограниченной ее рамками рыночной экономики.

Симптоматично, что современная Конституция КНР выделяет такой институт, как Единый патриотический фронт, объединяющий демократические партии, народные организации и социалистических трудящихся (непосредственно работающих в интересах государства и не пользующихся трудом других граждан в целях собственного обогащения). Патриотизм идентифицируется с приверженностью идеям социализма, а также объединения Китая и великого возрождения китайской нации. Соответственно, перспектива развития КНР законодательно определена как глобальное китайское объединение вне границ государства во имя нации посредством модернизированных институтов социализма.

Руководящая политическая роль закреплена за Коммунистической партией Китая - политической организацией социализма с китайской спецификой. Сувереном является народ, который осуществляет власть опосредованно через Всекитайское собрание народных представителей и местные собрания народных представителей, избираемых демократически, ответственных перед избирателями и подконтрольных им. Соответственно, партийное администрирование сдерживается механизмом народовластия. Органы исполнительной, судебной власти, прокуратуры формируются в КНР собраниями народных представителей и ответственны перед ними и подконтрольны им.

Исторически прослеживается параллель с конституционным строем РСФСР 1918 г. Дальнейшее развитие советской идеи институционализации суверенной власти народа в форме народовластия, ограничения функций Коммунистической партии сферой общественных движений и социальной культуры содержалось в незавершенном проекте новой Конституции СССР, которая готовилась в 1962-1964 гг. ${ }^{1}$ В проектных конституционных документах инициированы: учреждение законодательного органа власти - Верховного народного совета; ответственность представителей власти перед избирателями с правом на отзыв; предоставление общественным объединениям правомочия государственных органов, вовлечение их в социокультурную деятельность, в прямое, посредством избирательного права, формирование высших органов власти, обсуждение вопросов государственного строительства с проведением референдума; формализация права частной собственности, частных форм хозяйствования; сочетание рыночных и плановых механизмов в системе народного хозяйства. Эти идеи были реализованы в законодательстве запоздавших конституционных реформ начала 1990-х гг. Однако либерализация экономики, связанная с разрушением механизма регулирования, осложнялась структурным кризисом народного хозяйства и финансовой системы, уходившим своими корнями в кризис административно-командной советской системы 1950-х гг. Все это делало невозможным воплощение идей общенародного демократического государства.

Социалистическая рыночная модель КНР в правовом и институциональном содержании с очевидной национальной спецификой преломляет импульс советских «мягких» реформ периодов нэпа и либерализации, сочетая рыночные механизмы и многообразие форм собственности с приоритетом социалистической собственности, вторичностью коммерческого целеполагания, государ-

1 Государственный архив социально-политической истории (РГАСПИ). Ф. 84. Оп. 3. Материалы деятельности Микояна А.С. в Совете Министров СССР (Материалы Конституционной комиссии). Д. 37. Л. 2-14; Д. 43. Л. 5-36, 78-97, 120-170. 
ственно-административными ограничениями права частной собственности ${ }^{1}, \mathrm{c}$ плановой экономикой.

Основа экономической системы КНР, как закреплено в Конституции, это социалистическая общественная собственность на средства производства (общенародная и коллективная собственность трудящихся). Государство конституционно гарантирует укрепление и развитие социалистической экономики, основанной на государственной собственности.

Плановая система КНР, также с национальной спецификой, объединила плановые государственные задания, применяемые в СССР в период модернизации 1930-1940-х гг., с индикативным (рекомендательным) планированием, разработанным представителями советской экономической оппозиции во второй половине 1920-х гг.

Изучив прецедент экономического подъема периода нэпа, движение стоимостных пропорций между отраслями экономики, руководитель Конъюнктурного совета Госплана В.Г. Громан и сотрудники этой советской структуры разработали концепцию экстраполирования временных рядов и методику динамических коэффициентов [Громан 1925], доказав, что по мере преодоления разрушений или отставания экономики наращивают потенциал наиболее дезорганизованные и сложные хозяйственные структуры, которые устойчиво опережают в долгосрочном прогнозе относительно примитивные по организации структуры (производство продуктов и товаров широкого потребления). Современная КНР решает этот дисбаланс посредством товарно-производственной экспансии и жесткого администрирования.

Близкой точки зрения придерживались Л.Н. Крицман и С.Г. Струмилин, которые доказали, что на первом этапе модернизации/восстановления приоритетны рентабельные отрасли с быстрым оборотом капитала. По завершении этого макроэкономического процесса государство аккумулирует довольно значительную для техническо-отраслевой модернизации массу оборотных капиталов [Струмилин 1927]. В силу вступает закон затухающей кривой экономического роста: действующая структура народного хозяйства страны исчерпывает предел эффективности и нуждается в перестройке. А с перестройкой экономки всегда сопряжена и перестройка политическая [Галас 2007: 114-147].

Показательно, что в ходе разработки новой модели развития СССР в конце 1920-х - начале 1930-х гг. остро дискутировался вопрос о перспективном планировании, споры по которому перетекали в конфликт представлений о политическом (государственном) режиме, демократических ценностях, правах и свободах человека.

Тогда и сформировались три базовых идеи и методологических подхода к плановому макрорегулированию: административно-регулятивный, плановорыночный (с приоритетом народнохозяйственных интересов по отношению к рыночным процессам), индикативный (рекомендательный - с учетом специфики экономических районов, отраслей, региональных интересов). Последний называют еще организационно-производственным прогнозированием. Все три подхода находили применение в периоды экономических и геополитических кризисов в государствах Европы, США, Азиатско-Тихоокеанского региона.

Основателем первого подхода был Е.А. Преображенский. Согласно его концепции, регулятором экономических процессов в социалистическом государстве является закон социалистического накопления. Государство аккумулирует прибавочный продукт социалистических предприятий и ресурсы частного

\footnotetext{
1 Согласно закону, государство имеет право реквизировать или использовать частную собственность граждан при наличии общественных нужд, а также выплачивать им компенсацию.
} 
хозяйства (при помощи экономических и административных мер), подчиняя рынок.

Второй, планово-рыночный, подход получил развитие в работах В.А. Базарова и В.Г. Громана. Инновационные технологии и современное производство, по мнению В.А. Базарова, возможно развивать в зависимости от степени накопления капиталов и формирования соответствующей инфраструктуры [Базаров 1927; О методологии построения... 1926].

План рассматривался ими как система целевых и нормативно-числовых показателей, показывающих направление достижения оптимальных темпов экономического роста, согласованное с ресурсами народнохозяйственного механизма. Плановые задания, как предполагалось, должны определять направление и результат экономической деятельности государства, но пути и средства выполнения плана должны быть дифференцированными и корректироваться региональными и отраслевыми возможностями и интересами ${ }^{1}$. К сторонникам планово-товарной макроэкономики можно причислить А. Дезена. Главным инструментом макрорегулирования экономисту представлялась налоговая и финансово-кредитная политика² [Дезен 1927].

Индикативный подход связан с именами российских общественных деятелей, выдающихся экономистов, представителей экономической оппозиции 1920-х гг. и сторонников «мягких» реформ Н.Д. Кондратьева, Н.П. Макарова, А.В. Чаянова, А.Н. Челинцева, Н.П. Огановского, А.Л. Вайнштейна [Макаров 1927; Вайнштейн 1927; Кондратьев 1927; Челинцев 1927]. Идеологи индикативного прогнозирования отстаивали принцип равных возможностей для отраслей экономики и являлись противниками административного вмешательства в баланс между основными народнохозяйственными отраслями.

Особой, но не нашедшей должного понимания и реализации является конвергентная плановая концепция А.Н. Челинцева, который полагал, что желательное необходимо согласовывать с реально возможным, но и возможное следует расширять до задач желательного [Челинцев 1927: 48].

Современный Китай пытается балансировать между административно-регулятивным и планово-рыночным методами планирования.

Следующий этап развития идей советских «мягких» реформ государства связан с либерализацией политического (государственного) режима второй половины 1950-х - первой половины 1960-х гг. В процессе подготовки проекта третьей программы КПСС концептуальные основы реформ разрабатывались научно-исследовательскими институтами. Например, научные работники Всесоюзного научно-исследовательского института экономики сельского хозяйства под руководством А.И. Тулупникова представили обоснование системных преобразований в своей отрасли с привязкой к международным процессам и внутриполитическим задачам государства. В том числе предлагались ${ }^{3}$ :

- плановое использование объективного экономического закона стоимости;

- создание общегосударственных фондов накопления посредством регулирования розничных цен и установления закупочных цен на уровне затрат и внутрихозяйственных накоплений для расширенного социалистического производства;

- прямая, без государственного вмешательства система заказа сельхозпред-

\footnotetext{
1 Российский государственный архив экономики (РГАЭ). Ф. 4372. Оп. 1. Д. 191. Л. 241.

2 Планирование кредитования или кредитная политика. - Экономическая жизнь. 3 ноября 1923.

3 РГАСПИ. Ф. 586. Материалы по разработке проекта третьей программы КПСС. ОП. 1. Д. 13. Л. 27-64.
} 
приятием машин и материалов промышленным предприятиям (через магазины и другие торговые организации);

- развитие общенародной и кооперативной собственности в сельском хозяйстве при ведущей роли государственного сектора;

- система участия трудящихся в расширении социалистического производства путем отмены всех видов налогов и перехода к прямому определению прибавочного труда при установлении уровня оплаты труда в каждой из отраслей народного хозяйства.

Коллектив ученых Института экономики Академии наук СССР под руководством К.Н. Плотникова ${ }^{1}$ направил в ЦК КПСС аналитические материалы по экономическим проблемам строительства коммунизма в СССР, в т.ч. связанным с повышением эффективности капитальных вложений, и замечания, в которых предлагалось:

- устранить чрезмерную централизацию, сочетать централизованное государственное руководство с развитием инициативы республиканских и местных органов, с прямым участием трудящихся в управлении производством, приблизить плановое руководство к реальным условиям регионов;

- на основе возрастания неделимых фондов колхозов, трактуемых как институт общенародной собственности, объединения межколхозных предприятий (электростанций, перерабатывающих и сбытовых структур, строительных организаций и транспортных объединений) обеспечить высокотехнологичное развитие этого типа хозяйств, минимизировав дисбаланс между аграрным и индустриальным трудом;

- осуществить специализированное и комплексное многоотраслевое развитие в каждом экономическом районе, рациональное размещение промышленных предприятий и строительства.

В области использования товарно-денежных отношений для укрепления и развития хозяйственного расчета выдвинуты задачи:

- повысить роль рентабельности для материального стимулирования увеличения выпуска продукции и снижения ее себестоимости, обеспечить предприятиям в каждой отрасли и экономическом районе при выполнении плановых заданий получение прибыли в размерах, достаточных для удовлетворения материальной заинтересованности предприятий и коллектива его работников;

- совершенствовать систему цен (устанавливать экономически обоснованные цены, обеспечивающие возмещение затрат на производство и накопление, которые послужат условием развития хозрасчета, а также сбалансированных экономических отношений государственного сектора и колхозов, рабочего класса и крестьянства);

- широко использовать денежную форму учета и контроля за затратами «живого и овеществленного» труда и обеспечивать эффективность производства, устанавливать себестоимость и рентабельность производства;

- повысить товарность производства и на этой основе - развитие гарантированных денежных форм оплаты труда;

- использовать долгосрочные кредиты и средства неделимых фондов в качестве инструментов аккумуляции ресурсов для модернизации производства.

Китайским преломлением импульса советских «мягких» реформ является двухуровневая система хозяйствования (централизованная и децентрализованная, основой которой является семейный подряд, конституционно закрепленный для сельских коллективных экономических организаций). Трудящиеся этих организаций в пределах, установленных законом, наделены

${ }^{1}$ РГАСПИ. Ф. 586. ОП. 1. Д. 35. Л. 1-62. 
правом хозяйствования на приусадебных участках, выделенных в личное пользование горных участках, правом заниматься промыслом и животноводством. К социалистическому сектору экономики законодатель относит кооперативные хозяйства (снабженческо-сбытовые, производственные, потребительские и др.), созданные на базе коллективной собственности трудящихся, а также кооперативные хозяйства.

Двухуровневой является и банковская система КНР. Первый уровень Народный банк Китая, второй - специализированные государственные и коммерческие банки. Депозитные, кредитные и расчетные операции могут осуществляться кредитными кооперативами (городскими и сельскими), кредитными банками в городе.

Необщественный сектор экономики в КНР составляют индивидуальные и частные хозяйства, действующие в установленных законом рамках, отнесенные к субъектам права социалистической рыночной экономики, контролируемые и защищаемые (в пределах законных интересов и прав) государством.

Конституционно государство обязано повышать производительность труда и эффективность экономики, активность и технический уровень трудящихся, распространять новейшую технику и науку, совершенствовать систему управления экономикой, предприятиями, а также управление трудом. Государство ответственно за эффективное распределение средств накопления и потребления, развитие рыночной экономики.

Государственные предприятия в установленных законами пределах наделены правом самостоятельного хозяйствования, правом осуществлять демократическое управление посредством собраний представителей рабочих и служащих и в других формах. Коллективные экономические организации имеют право на самостоятельность (избирают и смещают управляющих) и независимое ведение хозяйственной деятельности в соответствии с законом.

Иностранным предприятиям и иным иностранным экономическим организациям, частным лицам государство разрешает осуществлять капиталовложения на территории КНР, экономическое сотрудничество с китайскими предприятиями, другими хозяйственными организациями в различных формах. Данные виды предприятий и организаций, смешанные предприятия, основанные на китайском и иностранном капитале, обязаны соблюдать законодательство, а их законные права и интересы находятся под охраной государства.

Специфика китайской государственной модели заключается и в реализации права граждан на труд, и в обязанности трудиться. При обязательности труда государство создает условия для трудоустройства, но не гарантирует его. Выход законодатель КНР нашел в особой форме гражданско-правового регулирования самозанятости ${ }^{1}$. Так, под индивидуальными торгово-промышленными предприятиями подразумеваются граждане, занимающиеся деятельностью в сфере промышленности и торговли в пределах, разрешенных законодательством, а также после получения разрешения и регистрации согласно закону. Под подрядными хозяйствами в деревне подразумеваются члены коллективных хозяйственных организаций в деревне, ведущие в пределах, разрешенных законодательством, товарное хозяйство в соответствии с договором подряда.

Такие формы экономической деятельности не требуют юридической регистрации, а их налогообложение соответствует налогообложению физических лиц. Формой самозанятости, применявшейся в РСФСР во времена нэпа, явля-

\footnotetext{
1 Общие положения гражданского права КНР (приняты на 4-й сессии Всекитайского собрания народных представителей 6-го созыва 12.04.1986, ред. 2009. Ст. 24-36. - Caŭm Chinalaw.center. Доступ: https://chinalaw.center/civil_law/china_general_principles_of_civil_law_revised_2009_russian/ (проверено 15.11.2018).
} 
лась артель. Под артелью подразумевалось объединение двух и более граждан, которые в соответствии с договором предоставляют денежные, материальные, технические средства и т.П., участвуют в ведении дел, совместно трудятся. Управление и пользование имуществом, внесенным участниками артели, осуществляются ими совместно. Имущество, накопленное в процессе деятельности артели, принадлежит всем его участникам.

Созданные на территории КНР совместные предприятия с китайским и иностранным капиталом (далее - китайские партнеры), кооперационные предприятия с китайским и иностранным участием и предприятия иностранного капитала, если они отвечают условиям юридического лица, после получения разрешения органов торгово-промышленной администрации и прохождения регистрации приобретают статус китайских юридических лиц. Как юридические лица они несут гражданскую ответственность имуществом, находящимся в их собственности.

Китайские партнеры ${ }^{1}$ должны создаваться на основании разрешения правительства КНР в соответствии с принципами равноправия и взаимной выгоды. Государство охраняет инвестиции иностранных партнеров в совместные предприятия, долю получаемой прибыли и прочие законные права и интересы иностранных партнеров в соответствии с утвержденными китайским правительством соглашениями, договорами, уставами ${ }^{2}$. При особых обстоятельствах с учетом общественных интересов и согласно установленному законом порядку в отношении совместных предприятий может осуществляться реквизиция при предоставлении соответствующей компенсации. Заключенные китайскими партнерами договоры, уставы и пр. обязательно передаются на утверждение государственным органам по вопросам внешнеэкономических связей и внешней торговли. На основании разрешения китайский партнер обязан обратиться в местный орган государственной торгово-промышленной администрации для регистрации для оформления удостоверения о хозяйствовании и приступить к деятельности ${ }^{3}$. Такой порядок учреждения, а также механизм функционирования этих субъектов идентичен советскому гражданскому законодательству периода нэпа.

Производственно-хозяйственные планы совместных предприятий надлежит представлять для согласования компетентным ведомствам, после чего все требования закрепляются хозяйственными договорами. Сырье, топливо, комплектующие и пр. эти субъекты гражданского права обязаны закупать преимущественно в Китае; за счет своих валютных средств они также могут закупать их на международном рынке.

\footnotetext{
1 Закон Китая (КНР) о совместных предприятиях с иностранным капиталом (принят 2-й сессией Всекитайского собрания народных представителей 5-го созыва 1 июля 1979 г; пересмотрен в соответствии с решением о пересмотре закона Китайской Народной Республики о совместных предприятиях с китайским и иностранным капиталом на 3-й сессии ВСНП 7-го созыва 04.04.1990, действует редакция 2016 г. - Сaŭm Chinalaw.center. Доступ: https://chinalaw.center/civil_law/china_sino-foreign_joint_ equity_enterprise_law_revised_2016_russian/ (проверено 15.11.2018).

2 В качестве формы совместного предприятия закреплена компания с ограниченной ответственностью. В зарегистрированном капитале совместного предприятия доля инвестиций иностранного партнера, как правило, не может быть ниже 25\%. Техника и оборудование, выступающие в качестве инвестиций иностранного партнера, должны быть действительно передовыми, отвечающими потребностям Китая. Если умышленно поставляемые отсталые техника и оборудование причиняют убытки, то убытки подлежат возмещению. По всем вопросам страхования совместного предприятия надлежит обращаться в китайские страховые компании.

3 Положения КНР о валютном контроле. Ст. 7-14. Утв. Указом № 193 Госсовета КНР от 29.01.1996. По решению Госсовета о пересмотре положений КНР о валютном контроле от 14.01.1997 в Положения были внесены поправки. Закон был повторно обнародован Указом № 211 Госсовета КНР от 14.01.1997 и вступил в силу со дня обнародования. - Информационно-аналитический портал «Бизнес в Китае». Доступ: https://asia-business.ru/law/law2/trade/controls/ (проверено 12.10.2018).
} 
Посредством налоговых преференций осуществляется поощрение совместных предприятий к сбыту продукции за пределами Китая. Допускается законодателем и сбыт продукции совместных предприятий посредством китайских внешнеторговых организаций, разрешен сбыт на китайском рынке. В интересах национальной экономики допускается создание филиалов рассматриваемых предприятий за пределами Китая.

В КНР государство поощряет и экспортную деятельность предприятий иностранного капитала, равно как и применение ими инновационных технологий ${ }^{1}$. Также законодательно регламентирована разрешительная форма учреждения этого вида субъектов правоотношений посредством специальных органов по внешнеэкономическим связям и внешней торговле Государственного совета либо органа, которому Государственный совет предоставит это право. Главное управление торгово-промышленной администрации производит проверку и осуществляет контроль за инвестированием иностранного капитала в предприятия.

В регулировании деятельности предприятий с иностранным капиталом $^{2}$ государство пытается сбалансировать институты социализма и рынка. Законодательно закреплена обязанность предприятий этого статуса соответствовать экономическим интересам КНР и задачам развития китайской нации, применять инновационные технологии и новейшее оборудование, развивать производство новой импортозамещающей и высококачественной продукции, экономно использовать энергоносители и сырьевые ресурсы, не наносить вред экологии. В случае закупки материальных ресурсов в КНР предприятие с иностранным капиталом при прочих равных условиях обязано отдавать предпочтение продукции китайских предприятий.

Такие предприятия являются экспортоориентированными: законодательно установлено процентное соотношение вывоза продукции в стоимостном отношении. Помимо этого, правительством КНР запрещено или ограничено создание предприятий с иностранным капиталом в определенных законодателем областях.

С другой стороны, предприятия с иностранным капиталом в границах разрешенной сферы хозяйственной деятельности действуют самостоятельно, например, в ценообразовательной политике в отношении производимой ими продукции с учетом цен мирового рынка, но не ниже рациональных экспортных цен. Предприятие самостоятельно разрабатывает и реализует план производственно-хозяйственной деятельности, о которых информирует отраслевое ведомство КНР по месту своего нахождения.

Парадигма дуализма рынка и социалистического сектора экономики, жесткого партийного администрирования и прямого народовластия, приоритетности национально-исторической специфики и стремление к международной экспансии так же, как и в России периода нэпа, в свете решения задачи модернизации и повышения темпов экономического роста, конфликта прямой демократии и классового детерминизма дает сбой и требует выбора модели среднесрочного и долгосрочного развития государства. Симптоматично в данном

1 Закон КНР о предприятиях с иностранным капиталом. Принят 12.04.1986 на 18-й сессии Всекитайского собрания народных представителей 9-го созыва. В ред. 2016 г. - Caŭm Chinalaw.center. Доступ: https://chinalaw.center/civil_law/china_foreign_investment_enterprise_law_revised_2016_russian/ (проверено 03.11.2018).

2 Положение Китайской Народной республики о применении закона о предприятиях с иностранным капиталом. Принято Государственным советом КНР 28.10.1990 (в ред. 2016 г.). Ст. 5-45. - Chinalaw.center. Доступ: https://chinalaw.center/civil_law/china_foreign_investment_enterprise_law_ revised_2016_russian/ (проверено 08.11.2018). 
контексте замедление темпов экономического роста, структурная безработица в KHP.

Как и в ситуации общественного кризиса в СССР, развившегося ко второй половине 1950-х гг, современный Китай переживает следующие противоречия:

- фактическое неравенство положения трудящихся при формальном гражданском равноправии, выражающееся в дифференцированном использовании общественных средств производства в разных отраслях народного хозяйства;

- диспропорцию в области распределения по труду при фактически неравном труде и неравных потребностях трудящихся; существенную дифференциацию в оплате труда;

- несогласованность товарного обмена с рыночными отношениями;

- разную степень удовлетворения потребностей трудящихся, занимающих различное положение в обществе.

Динамика экономического и политического развития КНР в среднесрочной перспективе будет сохранять зависимость от ведущих экономик мира и государств - лидеров мировой системы.

Для Китая приоритетными останутся внутренние проблемы: снижение ВВП на душу населения, уровня производительности труда и заработной платы, дисбаланс в народном хозяйстве, поддержание технологических инноваций и цифровизации, определенная ограниченность воздействия на мировые экономические, финансовые и инвестиционные процессы. Несмотря на комплексность проблем, требующих решения, КНР остается государством, обладающим экономическими и финансовыми, политическими и силовыми рычагами влияния на мировые процессы (главным образом, в Азиатско-Тихоокеанском регионе, в Восточной, Юго-Восточной Азии).

В инициативе Си Цзиньпина «Один пояс - один путь», не имеющей региональной геополитической привязки, создается прецедент «Большой Евразии», вбирающей страны Латинской Америки и Северной Африки. Множественности партнерства Китай предпочитает сотрудничество на основе двухсторонних договоров, которые по существу являются инструментом «мягкой силы». Как показывает сравнительный анализ идей «мягких» реформ, партнерство России и Китая в определенной мере основано на сопряжении двух государств с общей границей и историей.

Статья подготовлена по результатам исследований, выполненных за счет бюджетных средств по государственному заданию Финуниверситету 2018 года.

\section{Список литературы}

Базаров В.А. 1927. О наших хозяйственных перспективах и перспективных планах. - Экономическое обозрение. № 5. С. 34-36.

Вайнштейн А.Л. 1927. К критике пятилетнего перспективного плана развертывания народного хозяйства в СССР. - Экономическое обозрение. Вып. 7. C. 33-67.

Галас М.Л. 2007. Судьба и творчество русских экономистов-аграрников и общественно-политических деятелей А.Н. Челинцева и Н.П. Макарова: монография. М.: Изд-во ВГНА. 241 с.

Громан В.Г. 1925. О некоторых закономерностях, эмпирически обнаруживаемых в положении народного хозяйства. - Плановое хозяйство. № 1, 2.

Дезен А. 1927. Развитие промышленности и национальное накопление. Экономическое обозрение. № 4. С. 55-70. 
Кондратьев Н.Д. 1927. Критические заметки о плане развития народного хозяйства. - Плановое хозяйство. № 4. С. 3-6.

Макаров Н.П. 1927. Некоторые очередные вопросы методологии составления перспективных планов по сельскому хозяйству. - Пути сельского хозяйства. № 2. C. 42.

О методологии построения перспективных планов. 1926. - Плановое хозяйство. № 7. С. 9-13.

Струмилин С.Г. 1927. Индустриализация СССР и эпигоны народничества. Плановое хозяйство. № 7. С. 28-29.

Челинцев А.Н. 1927. К вопросу о методах и принципах составления перспективного плана по сельскому хозяйству. - Пути сельского хозяйства. № 2. C. 47-70.

GALAS Marina Leonidovna, Dr.Sci. (Hist.), Professor, Chief Researcher of the Department of Political Science and Mass Communications, Financial University under the Government of the Russian Federation (49 Leningradsky Ave, Moscow, GSP-3, Russia, 125993; MLGalas@fa.ru

\section{IMPULSE OF SOVIET-ERA IDEAS OF SOFT REFORMS IN THE MODERN STATE MODEL OF THE PEOPLE'S REPUBLIC OF CHINA}

Abstract. Russia historically builds mutually beneficial economic, political, defense-strategic relations and cultural ties with China. Modern geopolitics of the Russian Federation attaches particular importance to the Eurasian vector in its pragmatic understanding. Since the formation of the model of modern China is due to internal factors (state administration, labour, raw materials, production, distribution of resources, the structure of the national economy, cultural traditions, social systems and the composition of the population, etc.) and external ones (financial, investment, geopolitical, military-strategic, migration, infrastructure, state of the world market, etc.), the article traces the influence of the historical experience of the Soviet ideas of soft reforms on political and legal foundations of China's political system and its economic base.

The impact of the reform ideas of the west (in the political sense) is a matter for a separate study. In this aspect, the author introduces in wide circulation documents from the State Archive of Socio-political History (RGASPI).

Keywords: modern state model, Russian reforms, political and legal base, historical experience, soft power 